\title{
Tomografía computada de tórax en pediatría. Indicaciones actuales
}

\author{
Pediatric chest computed tomography: current indications
}

\author{
Dra Adriana Merchak A ${ }^{1}$, Dr Andrés Miranda-Merchak ${ }^{2}$ \\ 1.- Servicio de Radiología, Clínica Indisa \\ 2.- Residente Radiología, Universidad de los Andes
}

\begin{abstract}
PEDIATRIC CHEST COMPUTED TOMOGRAPHY: CURRENT INDICATIONS
The study of respiratory diseases is a common practice in pediatrics. Images play an important role and multidetector computed tomography (MDCT) is actually a significant pediatric modality. MDCT has advantages over conventional computed tomography . It enables radiation dose and intravenous contrast volume reduction, fast examinations, volumetric acquisitions during breathhold without artifacts, high quality images and multiplanar reformats. This article will review MDCT indications including lung nodules, chest masses, airway diseases, cervicothoracic, diaphragmatic and yuxtadiaphragmatic lesions, chest wall disease, vascular study, infections and congenital malformations. In conclusion, newer technologies in CT are safer and have extended indications in pediatrics.
\end{abstract}

Key words: computed tomography, chest, indications, pediatrics

\section{RESUMEN}

El estudio de enfermedades que afectan el sistema respiratorio es una práctica cotidiana en pediatría. Las imágenes cumplen un rol muy importante y la tomografía computada multicorte (TCMC) tan alejada inicialmente de los niños tiene actualmente un rol muy importante. La TCMC ha aumentado significativamente el número de patologías posibles de estudiar ya que presenta ventajas en comparación con la tomografía convencional. Permite reducir la dosis de radiación y de volumen de contraste endovenoso, es un exámen extremadamente rápido, se consiguen adquisiciones volumétricas en apnea sin artefactos, imágenes de muy buena calidad y reconstrucciones multiplanares. Este artículo revisa las indicaciones de estudio con tomografía computada de nódulos pulmonares, masas torácicas, vía aérea, lesiones cervicotorácicas, diafragmáticas o yuxtadiafragmáticas, de la caja torácica, estudio vascular, infecciones y malformaciones congénitas. En conclusión, las nuevas tecnologías de tomografía computada han ampliado las indicaciones en pediatría, convirtiéndose en exámenes más seguros y altamente resolutivos.

Palabras claves: tomografía computada, tórax, indicaciones, pediatría

\section{INTRODUCCIÓN}

La necesidad de estudiar las enfermedades que afectan el sistema respiratorio es muy frecuente en pediatría. En algunas es prioritario el diagnóstico precoz, en otras su seguimiento, sean enfermedades congénitas 0 adquiridas. El estudio por imágenes juega un rol muy importante y la tomografía computada tan alejada inicialmente de los niños ha pasado a tener un rol protagónico.

La nueva tecnología en tomografía denominada multidetector ha aumentado significativamente el número de enfermedades posibles de estudiar ya que presenta ventajas importantes al ser comparada con la tecnología convencional. Permite reducir la dosis de radiación y de volumen de contraste endovenoso, adquisiciones volumétricas en apnea, sin artefactos por respiración, imágenes de muy buena calidad y rápidas de obtener y reconstrucciones multiplanares(1).

\section{Correspondencia:}

Dra. Adriana Merchak A.

Clínica Indisa

Av. Los Conquistadores 1810, Providencia, Santiago

E-mail: adrianamerab@yahoo.com
TÉCNICA

Aspectos generales

El uso de tomografía computada en niños desde sus inicios ha tenido dificultades técnicas, debido por un lado a los movimientos del paciente pediátrico y por otro a la ausencia de grasa visceral, logrando imágenes de regular calidad (2).

Actualmente la tecnología permite realizar TCMC, con la ventaja de dosis de radiación muy baja, obteniendo una única adquisición con posterior reformateo de imágenes de muy buena calidad.

Además, dada la rapidez de los estudios se ha disminuido el volumen de contraste requerido, y consecuentemente a una disminución significativa en el uso de sedación. Hay que destacar que los nuevos equipos son bastante silenciosos en comparación con los antiguos, lo que permite una mayor colaboración del paciente pediátrico.

La introducción de TCMC ha permitido aumentar la gama de patologías a estudiar, logrando un reconocimiento adecuado de la anatomía ya que, debido a su rapidez se han disminuido los artefactos por movimiento. Así, es posible estudiar estructuras vasculares y de vía aérea con técnicas específicas como angiografía por tomografía, estudios dinámicos 
y endoscopías virtuales. Permite realizar reconstrucciones multiplanares lo que da adecuada valoración de masas y su relación con los órganos vecinos (3).

\section{TIPOS DE TCMC (2)}

Técnica estándar: constituye la gran mayoría de las TCMC. El tórax es estudiado en forma completa incluyendo pulmones y mediastino. Se caracteriza por cortes de mayor grosor, según la edad del paciente. Se puede realizar con y sin contraste.

Alta resolución: se usa para evaluar áreas localizadas. Se caracteriza por cortes secuenciales finos obteniendo zonas de mayor definición y detalle. Los cortes realizados son de 2 a $3 \mathrm{~mm}$, con algoritmo de reconstrucción de alta resolución. Se usa para estudio de vía aérea central por ejemplo estenosis traqueobronquial, lesión endobronquial o estudio de anomalía vascular. Las reconstrucciones multiplanares y 3D son muy útiles para caracterizar las anomalías de la vía aérea. También se utilizan en estudio de lesiones cervicotorácicas, patología diafragmática 0 yuxtadiafragmáticas 0 enfermedades que afecten la caja torácica.

Baja dosis y alta resolución: se utiliza para el estudio de enfermedad pulmonar crónica. Se caracteriza por valorar muy bien el parénquima pulmonar y el intersticio, sin embargo no da buena definición de mediastino. Se realizan cortes finos de $1 \mathrm{~mm}$ de grosor a intervalos de $10 \mathrm{~mm}$ para el estudio inicial y cortes de $1 \mathrm{~mm}$ a intervalo de $20 \mathrm{~mm}$ para el seguimiento de la patología pulmonar crónica (4). En el caso de los prematuros, la secuencia es de cortes de $1 \mathrm{~mm}$ cada $5 \mathrm{~mm}$ debido al pequeño tamaño del tórax. Se utilizan algoritmos de reconstrucción de alta resolución que permiten muy buena definición de bordes y resolución espacial. Esta técnica logra disminuir la dosis de radiación en niños entre un 70 a $80 \%$, siendo equivalente a la dosis de radiación de una radiografía de tórax frontal y lateral en los estudios de seguimiento (5). especiales :

Dentro de esta técnica se debe considerar técnicas

- tomografía de baja dosis localizada: se realizan 3 04 cortes específicos en el punto del parénquima pulmonar a analizar, útil en la valoración de bronquiectasias, enfisema lobar o neumonía cavitada.

- tomografía de cortes limitados: para seguimiento de enfermedades pulmonares crónicas, útil en pacientes con fibrosis quística, displasia broncopulmonar, neumonías intersticiales, histiocitosis o proteinosis alveolar.

- tomografía con cortes espiratorios: realizada en posición decúbito supino en niños que cooperan con una espiración forzada. Se realizan 3 cortes espiratorios: a nivel superior, medio e inferior. En niños pequeños que no cooperan con la respiración se realiza en decúbito lateral o prono, permitiendo en el primer caso obtener adecuada valoración de cada pulmón tanto en inspiración como en espiración y en el segundo caso obtener adecuada valoración de los segmentos posteriores de ambos campos pulmonares. Podremos hacer evidente alteraciones de la vía aérea pequeña demostrando zonas de atrapamiento aéreo que pueden no ser adecuadamente evidentes en los cortes en inspiración (Figura 1).

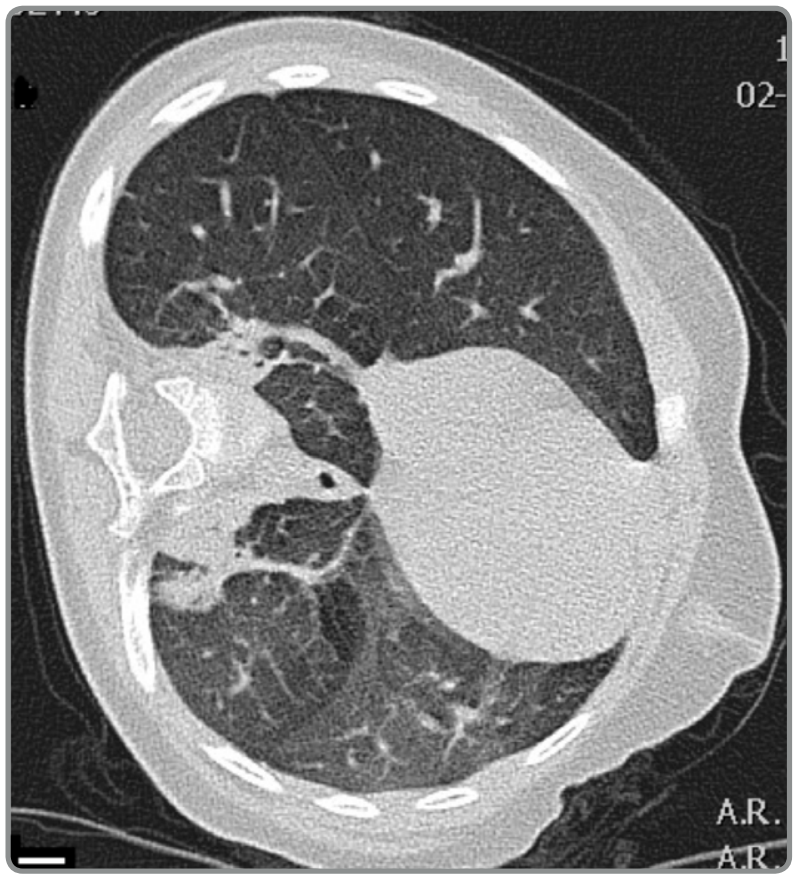

Figura 1.

Imagen en decúbito lateral: utilidad en niños pequeños para demostrar atrapamiento aéreo (zona superior), en espiración.

TCMC dinámico: permite estudiar el pulmón y la vía aérea en inspiración y en un segundo barrido en espiración forzada, muy útil para el estudio de traqueomalacia o de compresión dinámica de la vía aérea. Tiene la desventaja que requiere de la cooperación del paciente para demostrar el máximo cambio de calibre de la vía aérea. En los niños que no cooperan se debe utilizar técnica de ventilación controlada con el niño sedado sin intubar o si no es posible, debe realizarse adquisición de imágenes a través del ciclo respiratorio en un mismo punto, con respiración tranquila (6).

\section{INDICACIONES}

Las principales indicaciones en pediatría incluyen el estudio de nódulos pulmonares, masas torácicas, estudio de la vía aérea, lesiones que afectan regiones cervicotorácicas, lesiones diafragmáticas o yuxtadiafragmáticas, de la caja torácica y estudio vascular.

Otras indicaciones incluyen estudio de infecciones y de malformaciones congénitas. 


\section{NÓDULOS PULMONARES}

La TCMC ha mejorado en más de un 10\% la detección de nódulos pulmonares con respecto a la tomografía convencional. En general, el estudio se realiza en pacientes en apnea en los que se hacen cortes secuenciales, sin uso de contraste (Figura 2). En niños que no pueden realizar apnea se obtiene con respiración tranquila, lo que no produce una pérdida significativa de información en la detección de metástasis pulmonares.

En general, se usa reconstrucciones con solapamiento de las imágenes de un 50\% lo que mejora la pesquisa de nódulos y disminuye posibles artefactos.

Las reconstrucciones en los distintos planos del espacio permiten valorar la relación que tienen los nódulos con las distintas estructuras anatómicas y vasculares (7).

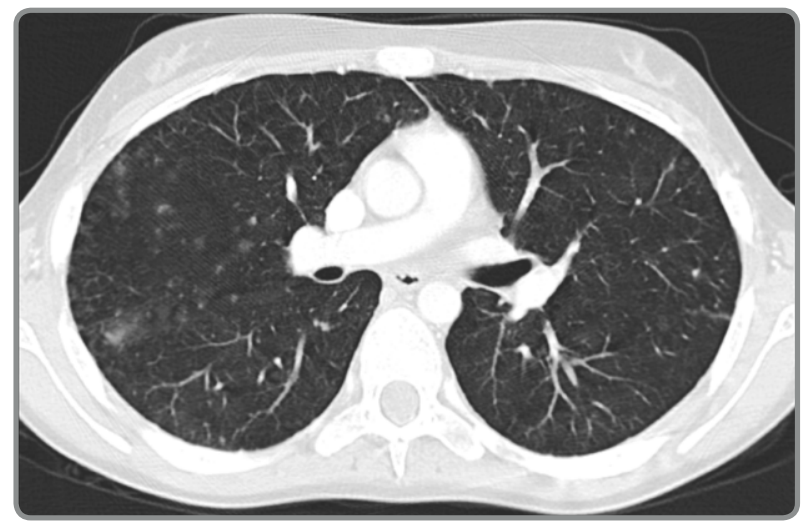

Figura 2.

La imagen muestra múltiples metástasis pulmonares de pequeño tamaño diseminadas en ambos campos pulmonares.

\section{MASAS PULMONARES Y MEDIASTÍNICAS}

Para estudiarlas se usa el TCMC estándar con contraste, lo que permite una adecuada definición anatómica de las distintas estructuras. El examen se realiza posterior a la inyección del $100 \%$ del contraste, lo que permite diferenciar adecuadamente estructuras mediastínicas de masas y adenopatías. EI TCMC es el examen de elección para valorar masas mediastínicas anteriores 0 medias. Las posteriores también se pueden valorar con esta técnica, sin embargo en ellas se prefiere la resonancia magnética por la relación que estas masas puedan tener con la columna vertebral y médula espinal $(3,7)$.

\section{ETAPIFICACIÓN DE MASAS TUMORALES Y SU SEGUIMIENTO}

Es una indicación habitual de TCMC ya que identifica la masa, su extensión, relación con órganos vecinos e infiltración, encarcelamiento vascular y existencia de adenopatías. Las reconstrucciones 3D permiten adecuada valoración de la masa y relación con órganos vecinos.
Habitualmente los estudios incluyen tórax y abdomen, lo que puede realizarse con una sola dosis de contraste obteniendo imágenes de excelente calidad.

\section{ESTUDIO DE MASAS TORÁCICAS CONGÉNITAS}

Entre ellas se cuenta el estudio del secuestro pulmonar y de la malformación adenomatoide quística actualmente denominada malformación congénita de la vía aérea pulmonar (CPAM) $(7,8)$. EI TCMC supera a la resonancia magnética en la valoración del secuestro pulmonar porque además de ver la anatomía vascular permite valorar adecuadamente el parénquima pulmonar (Figura 3).

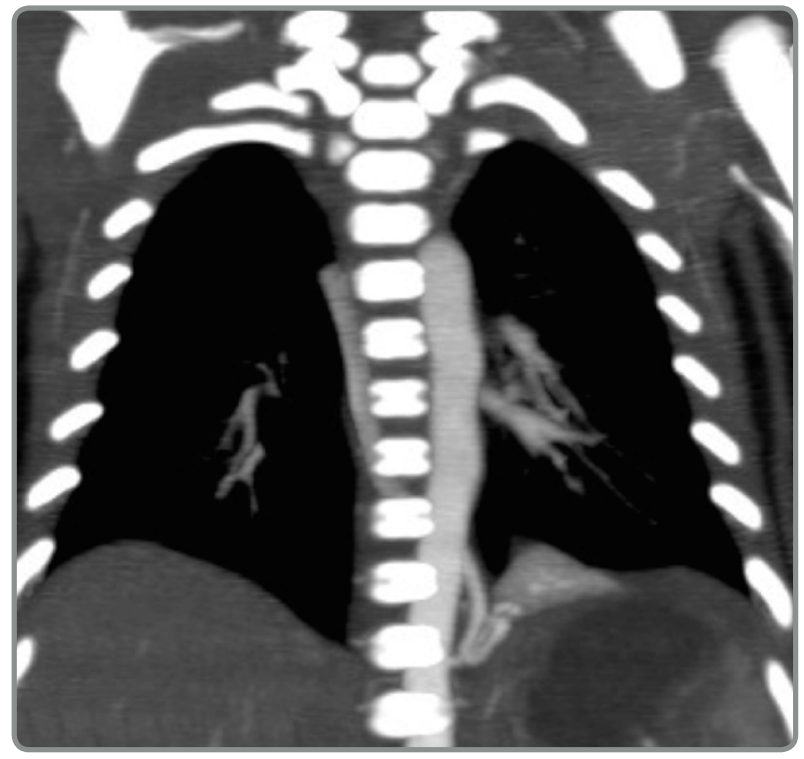

Figura 3.

Reconstrucción coronal que muestra el vaso nutricio que emerge de la aorta torácica hacia el secuestro pulmonar basal izquierdo.

\section{ESTUDIO DE MASAS CERVICOTORÁCICAS, DE CAJA TORÁCICA, LESIONES DIAFRAGMÁTICAS O YUXTADIAFRAGMÁTICAS(9)}

Se valoran adecuadamente con TCMC con uso de contraste y posteriormente se realizan las reconstrucciones multiplanares y 3D que mostrarán adecuadamente las zonas de los ápices pulmonares y las cercanas al diafragma.

En cuanto a las masas que afectan la pared torácica, el TCMC es superior a la resonancia magnética en la valoración de la disrupción de la cortical del hueso y de la detección de calcificaciones. A la inversa, la resonancia es mejor en la valoración de las partes blandas y en el compromiso infiltrativo medular. Las reconstrucciones 3D demuestran con gran claridad la alteración existente (Figura 4). 


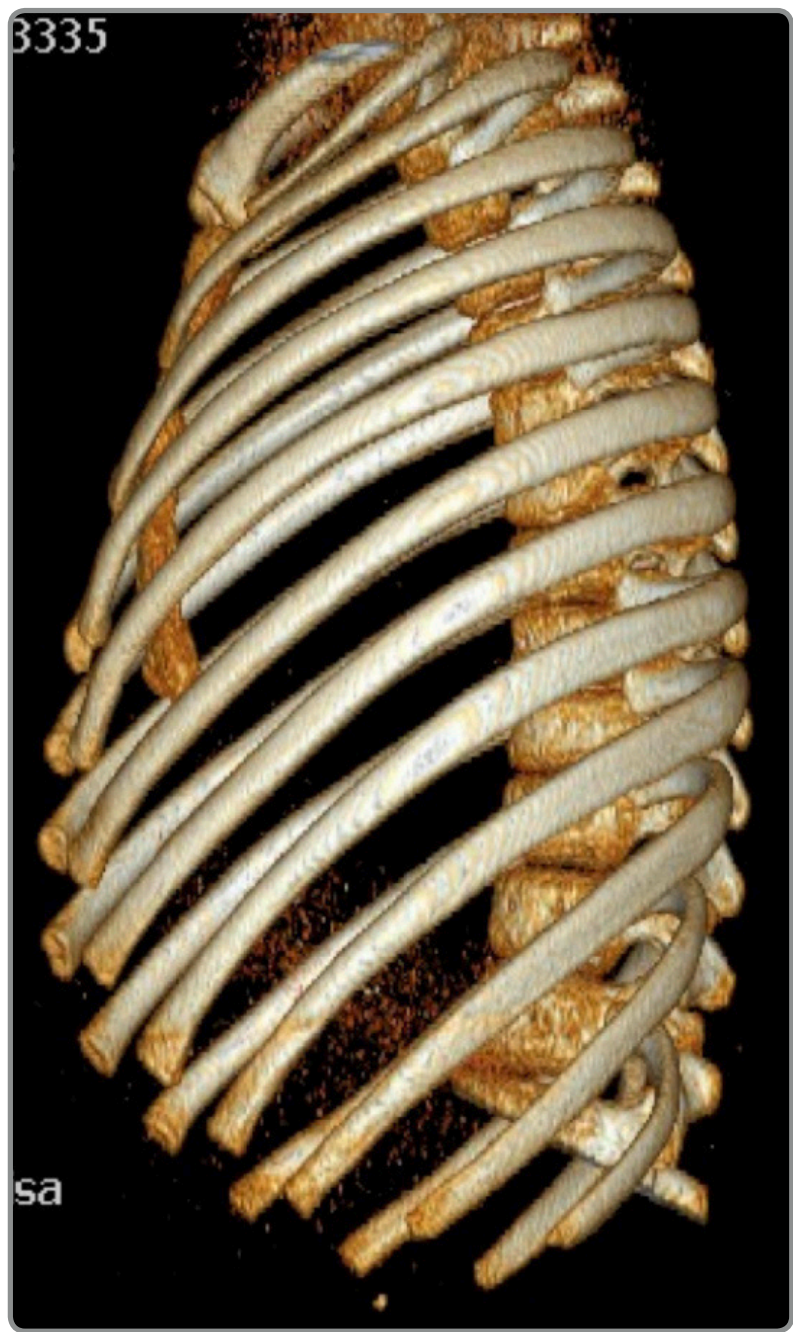

Figura 4.

Reconstrucción 3D que muestra la deformidad del esternón en un pectus excavatum

ESTUDIO DE INFECCIONES PULMONARES, PLEURALES, TRAUMA TORÁCICO, MALFORMACIONES VASCULARES $Y$ TROMBOEMBOLISMO PULMONAR.

Todas estas indicaciones pueden ser acabadamente estudiadas con TCMC y angiografía por tomografía computada. El estudio multifásico permite la detección de sangrado activo en el paciente politraumatizado.

\section{ESTUDIO VASCULAR}

Se realiza con angiografía por tomografía computada. Permite valorar en las distintas fases vasculares: arterial, venosa y tardía los vasos del tórax. Se obtienen imágenes de muy alta definición permitiendo la valoración de vasos que nutren y drenan una masa torácica como por ejemplo un secuestro pulmonar, 0 bien analizar anomalías vasculares de aorta, arterias pulmonares o sistema venoso, como es el caso de anillos vasculares, etc. Las reconstrucciones multiplanares caracterizarán la anatomía vascular adecuadamente y su relación con posibles masas torácicas.

Se sabe que la resonancia magnética es la técnica de elección en el estudio del mediastino sin embargo, la angiografía por tomografía es una técnica alternativa en aquellos pacientes que no pueden tolerar exámenes largos dando excelente información con nula o mínima sedación en los niños. Esta indicada para la evaluación de cardiopatías congénitas, estudio de anillos vasculares, coartación aortica, trauma aórtico, vasculitis, drenajes venosos pulmonares anómalos, secuestro pulmonar (10).

\section{ESTUDIO DE VÍA AÉREA}

Se realiza con TCMC con corte fino en apnea en niños cooperadores o con respiración tranquila en niños que no cooperan, lo que permite valorar la anatomía y realizar reconstrucciones de alta resolución y buena definición.

El TCMC de la vía aérea demuestra hasta el 95\% de la anatomía segmentaria y permite adecuada valoración de los bronquios de la língula, los que no son fáciles de ver en la tomografía convencional. Esta indicado para valorar anomalías congénitas como estenosis o atresia bronquial, complicaciones posteriores a cirugía pulmonar, posteriores a trasplante, permite valorar fístulas, lesiones endobronquiales, cuerpos extraños y stents (11). Las reconstrucciones multiplanares son de gran utilidad en la planificación preoperatoria (Figura 5).

\section{CONCLUSIONES}

La TCMC en pacientes pediátricos da la posibilidad de realizar excelentes estudios por imágenes de alta calidad. Existen distintas técnicas que permiten obtener información determinante, dependiendo de la indicación del examen y los antecedentes clínicos. El uso de medio de contratse se indica principalmente para caracterizar masas y anatomía vascular.

La TC de baja dosis es el examen de elección para el estudio y seguimiento de las enfermedades pulmonares crónicas. Debe utilizarse técnicas especificas para evidenciar compromiso de la vía aérea pequeña en niños.

En resumen, las nuevas tecnologías de tomografía computada han ampliado las indicaciones en pediatría, convirtiéndose en exámenes más seguros y altamente resolutivos. 


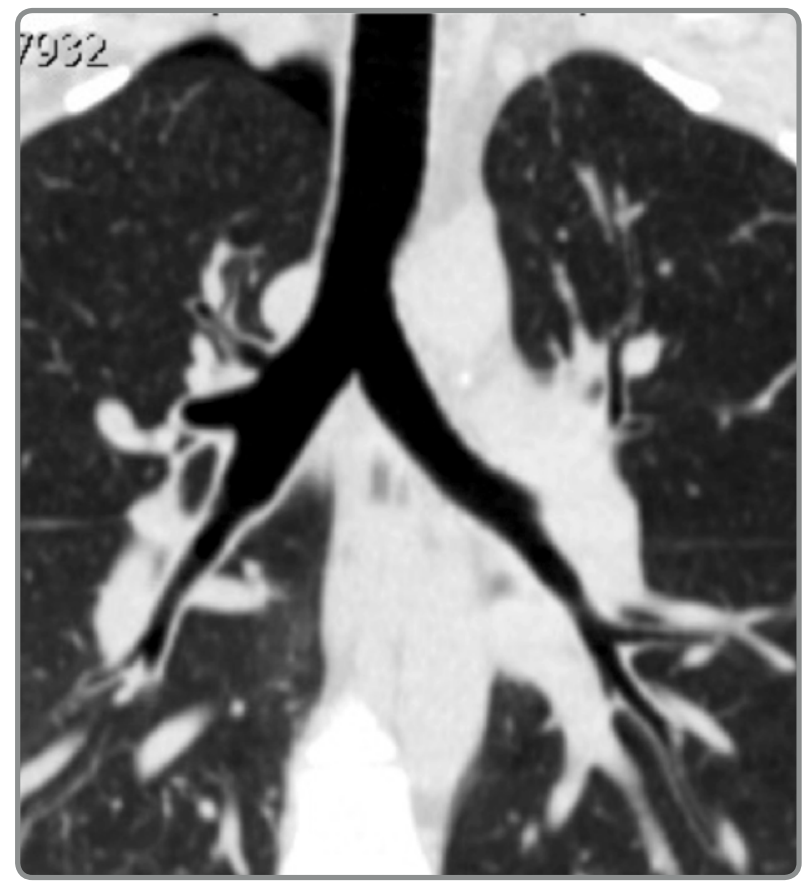

Figura 5.

Reconstrucción coronal que demuestra la vía aérea central y su relación con las estructuras vasculares.

\section{Los autores no presentan conflictos de intereses.}

\section{REFERENCIAS}

1. Puderbach $M$, Kauczor HU. Can lung MR replace lung CT? Pediatr Radiol 2008 ;38 Suppl 3:S439-S451

2. Lucaya J, Strife J. Helical chest CT. Pediatric chest imaging. Springer-Verlag Heidelberg New York, Germany, 2002, p 33 - 53 3. Frush DP, Donnelly LF. Helical CT in children: technical considerations and body applications. Radiology.1998;209:37-48 4. García-Peña P, Boixadera H, Barber I, Toran N, Lucaya J, Enríquez $G$. Thoracic findings of systemic diseases at highresolution CT in children. Radiographics $2011 ; 31: 465-482$

5. O'Connor OJ, Vandeleur M, McGarrigle AM, Moore N, McWilliams SR, McSweeney SE, O'Neill M, Ni Chroinin M, Maher MM. Development of low-dose protocols for thin-section CT assessment of cystic fibrosis in pediatric patients. Radiology 2010;257:820-829

6. Yedururi S, Guillerman RP, Chung T, Braverman RM, Dishop MK, Giannoni CM, Krishnamurthy R. Multimodality imaging of tracheobronchial disorders in children. Radiographics 2008;28:e29

7. Biyyam DR, Chapman T, Ferguson MR, Deutsch G, Dighe MK. Congenital lung abnormalities: embryologic features, prenatal diagnosis, and postnatal radiologic-pathologic correlation. Radiographics 2010;30:1721-1738
8. Kao SW, Zuppan CW, Young LW. AIRP best cases in radiologicpathologic correlation: type 2 congenital cystic adenomatoid malformation (type 2 congenital pulmonary airway malformation). Radiographics 2011;31:743-748

9. Calloway EH, Chhotani AN, Lee YZ, Phillips JD. ThreeDimensional Computed Tomography (3-D CT) for Evaluation and Management of Children with Complex Chest Wall Anomalies: Useful Information or Just Pretty Pictures? J Pediatr Surg. 2011; 46(4). doi:10.1016

10. Merchak A. Computed angiotomography in pediatrics: experience in a children's hospital. Rev. Chil. Radiol 2008;14:7379

11. Gipson MG, Cummings KW, Hurth KM. Bronchial atresia. Radiographics $2009 ; 29: 1531-1535$ 